\title{
The antipsychotic drug pimozide inhibits cell growth in prostate cancer through suppression of STAT3 activation
}

\author{
WEI ZHOU $^{1 *}$, MING-KUN CHEN $^{2 *}$, HAO-TAO YU ${ }^{1}$, ZHI-HONG ZHONG ${ }^{1}$, \\ NAN CAI $^{3}$, GUAN-ZHONG CHEN ${ }^{3}$, PING ZHANG ${ }^{1}$ and JIA-JIE CHEN ${ }^{3}$ \\ ${ }^{1}$ Department of Orthopedics, The Third Affiliated Hospital of Guangzhou Medical University, Guangzhou; \\ ${ }^{2}$ Department of Urology, The Third Affiliated Hospital of Southern Medical University, Guangzhou; ${ }^{3}$ Vaccine Research \\ Institute of Sun Yat-sen University, The Third Affiliated Hospital of Sun Yat-sen University, Guangzhou, P.R. China
}

Received August 15,2015; Accepted September 28, 2015

DOI: 10.3892/ijo.2015.3229

\begin{abstract}
Currently, drug discovery and development for clinical treatment of prostate cancer has received increased attention, specifically the STAT3 inhibitor. Our previous study reported that the neuroleptic drug pimozide had antitumor activity against hepatocellular carcinoma cells or stem-like cells through suppressing the STAT3 activity. In the present study we demonstrate that pimozide inhibits cell growth and cellular STAT3 activation in prostate cancer cells. Our results showed that pimozide inhibited prostate cancer cell proliferation in a dose- and time-dependent manner by inducing G1 phase cell cycle arrest, downregulated the ability of colony formation and sphere forming, as well as suppressed cells migration in both DU145 and LNCaP cells. Surprisingly, pimozide reduced the basal expression of phosphorylation STAT3 at tyrosine 705 and reversed the expression of phosphorylation of STAT3 induced by IL-6 addition, suggesting that pimozide can suppress cellular STAT3 activation. Thus, the antipsychotic agent pimozide may be a potential and novel therapeutic for patients with advanced prostate cancer.
\end{abstract}

\section{Introduction}

Currently, drug repurposing, meaning that is to discover new applications of existing or abandoned pharmacotherapies, is an effective approach for developing novel pharmacotherapies

Correspondence to: Dr Jia-Jie Chen, Vaccine Research Institute of Sun Yat-sen University, The Third Affiliated Hospital of Sun Yat-sen University, No. 600 Tianhe Road, Guangzhou 510630, P.R. China E-mail: tieniu03@126.com

Professor Ping Zhang, Department of Orthopedics, The Third Affiliated Hospital of Guangzhou Medical University, No. 63 Duobao Road, Guangzhou, P.R. China

E-mail: 644459349@qq.com

*Contributed equally

Key words: pimozide, prostate cancer, STAT3 signaling, STAT3 inhibitor, translational medicine in treating cancer (1). Many existing drugs approved by FDA, such as metformin (2), aspirin (3) and disulfiram (4), have demonstrated anticancer effects in addition to their original uses. Consequently, more approved drugs need to be found to inhibit the cancer cell growth, leading to increased choice and enhancement of the effectiveness of antitumor therapy.

Prostate cancer is one of the most common cancers worldwide, as well as a frequent cause of cancer-related death (5). Many patients with prostate cancer, having a poor prognosis, often developed resistant to the common therapies, including androgen deprivation treatment and cytotoxic drugs (6). The transcription factor STAT3 is constitutively active and has been associated with prognosis and progression in human prostate cancer (7). STAT3 is involved in oncogenesis, cell proliferation, angiogenesis, self-renewal and drug resistance. Several studies have suggested that inhibition of STAT3 signaling induces apoptosis, prevents metastasis and overcomes drug-resistance in prostate cancer $(8,9)$. Thus, it is indicated that targeting STAT3 activation appears to be a promising treatment strategy for patients with advanced prostate cancer.

Pimozide is an FDA-approved compound used to clinically treat chronic psychosis, Tourette syndrome and resistant tics (10). Moreover, in previous studies, pimozide was shown to have anticancer effect on various carcinomas and leukemia, including melanoma (11), breast cancer (12) and myelogenous leukemia $(13,14)$. The neuroleptic agents pimozide inhibited cell proliferation and induced apoptosis in human breast cancer cell line MCF-7 $(12,15)$. In addition, pimozide suppressed the self-renewal capacity of chronic myelogenous leukemia cells by inhibiting STAT5 activity (13). Furthermore, our previous study showed that pimozide inhibited maintenance and tumorigenicity of hepatocellular carcinoma stem-like cells through suppressing the STAT3 activity (16). However, whether pimozide shows anticancer effect and inhibits the STAT3 activation mechanically in prostate cancer cells have not yet been fully determined.

The aim of the present study was to investigate the antitumor effects of the neuroleptic drug pimozide on prostate cancer cells. The results showed that pimozide inhibited prostate cancer cell proliferation, colony formation and sphere formation by inducing G1 phase cell cycle arrest. In addition, 
pimozide inhibited cell migration of prostate cancer cells in the Transwell system. Importantly, pimozide suppressed the basal STAT3 activation and rescued STAT3 activation induced by IL-6 addition in prostate cancer cells. Therefore, the antipsychotic agent pimozide may be a potential treatment strategy for patients with advanced prostate cancer.

\section{Materials and methods}

Cell lines and cell culture. Human prostate cancer cell lines DU145, LNCaP, PC3M, 22RV1 and BHP-1 (The Third Affiliated Hospital of Sun Yat-sen University, Guangzhou, China) were cultured in Dulbecco's modified Eagle's medium (DMEM; Gibco, Grand Island, NY, USA) containing 10\% fetal bovine serum (FBS; Sigma, St. Louis, MO, USA). All cancer cell lines were cultured in incubator with $5 \% \mathrm{CO}_{2}$ at $37^{\circ} \mathrm{C}$.

Cell proliferation assay using MTT. Cell proliferation was performed by MTT colorimetric assay. Human prostate cancer cell lines DU145, LNCaP, PC3M, 22RV1 and BHP-1 were seeded into 96-well culture plates with 2,500 cells/well. Subsequently, cells were treated with pimozide at different concentration for various time intervals (24, 48 and $72 \mathrm{~h}$ ). Next, each well was added with MTT solution and incubated for $4 \mathrm{~h}$ at $37^{\circ} \mathrm{C}$. The supernatant fluid was removed, and DMSO solution was added. Absorbance value was finally measured using the microplate reader at $490 \mathrm{~nm}$ (BioTek Instruments Inc., Winooski, VT, USA).

Cell cycle assay. Cell cycle was determined by propidium iodide (PI; BD Biosciences Clontech, Palo Alto, CA, USA) staining. Briefly, equal amounts of cells were seeded in 6-well plates and treated with pimozide at different concentration for $48 \mathrm{~h}$. The cells were harvested, washed with phosphatebuffered saline (PBS) containing $0.1 \%$ BSA, and then, cold absolute ethanol was added while vortexing the cells. PI buffer (40 $\mu \mathrm{g} / \mathrm{ml}$, containing $100 \mu \mathrm{g} / \mathrm{ml}$ RNase) was added, and the cells were analyzed by flow cytometry.

Colony formation assay. Cells with different concentrations of pimozide $(7.5$ and $15 \mu \mathrm{M})$ were plated in $10 \%$ FBS medium for 7 days. Cells were stained with $0.5 \%$ crystal violet in $20 \%$ ethanol and photographed. The morphology and the number of colonies were counted under stereomicroscope.

Sphere formation assay. Sphere formation assay was performed as previously described (17). To establish sphere cultures, single cells were cultured in $200 \mu \mathrm{l}$ of serum-free DMEM/F12 medium (Gibco) supplemented with $20 \mathrm{ng} / \mathrm{ml}$ human recombinant epidermal growth factor (EGF; PeproTech, Rocky Hill, NJ, USA), $20 \mathrm{ng} / \mathrm{ml}$ human recombinant basic fibroblast growth factor (bFGF; PeproTech), and B27 (1:50; Gibco). Cells at a density of 500 cells/well were cultured in ultra-low attachment plates. Pimozide was added to the cells at the beginning. After plating for 7 days, all spheres in each well were photographed.

Transwell migration assay. Cells $\left(1 \times 10^{5}\right)$ in serum-free medium were seed in the upper compartment of a Transwell chamber
(Corning Incorporated, Corning, NY, USA). Pimozide was added at 7.5 and $15 \mu \mathrm{M}$. After incubation for $48 \mathrm{~h}$, the migrated cells on the lower membrane were counted after staining with $0.1 \%$ crystal violet. Results were shown as average from at least three independent experiments.

Western blot assay. Equal amounts of protein from cells sample harvested with RIPA lysis buffer were subjected to electrophoresis in SDS-polyacrylamide gel and transferred to nitrocellulose membrane (Merck Millipore, Billerica, MA, USA). Blots were detected using primary antibodies against GAPDH (Ambion, Austin, TX, USA), p21, Nanog, E-cadherin, N-cadherin, phospho-STAT3(Tyr705) (pY-STAT3), STAT3 (Cell Signaling Technology, Beverly, MA, USA), cyclin D1, c-Myc and $\beta$-actin (Santa Cruz Biotechnology, Santa Cruz, CA, USA). Antibody binding was detected with an enhanced chemiluminescence kit (Sigma).

Statistical analysis. The data were presented as the mean \pm SD and analyzed using the GraphPad Prism 6.0 (GraphPad Software, Inc., La Jolla, CA, USA). Student's t-test was used to compare the difference between two groups. The level of significance was set at $\mathrm{P}<0.05$. The statistically significant results are shown as $\mathrm{P}<0.05, \mathrm{P}<0.01$.

\section{Results}

The antipsychotic agent pimozide inhibits cell proliferation of prostate cancer cells in a dose-and time-dependent manner. Initially, we examined whether the antipsychotic agent pimozide (structure shown in Fig. 1A) has anti-proliferative effect in prostate cancer cells using MTT colorimetric assay. Human prostate cancer cells DU145, LNCaP, PC3M, 22RV1 and BHP-1 were exposed to a series of concentrations $(0,5$, 10,15 and $20 \mu \mathrm{M}$ ) of pimozide for 24,48 and $72 \mathrm{~h}$. As shown in Fig. 1B-F, pimozide inhibited the proliferation of these five cell types dose- and time-dependently. The $\mathrm{IC}_{50}$ values at 24 , 48 and $72 \mathrm{~h}$ were $12.62 \pm 2.60,10.74 \pm 1.21$ and $6.541 \pm 0.85 \mu \mathrm{M}$ for DU145, $14.10 \pm 2.05,11.90 \pm 3.05$ and $7.21 \pm 0.70 \mu \mathrm{M}$ for $\mathrm{LNCaP}, 12.07 \pm 2.54,8.90 \pm 1.18$ and $9.19 \pm 1.21 \mu \mathrm{M}$ for PC $3 \mathrm{M}, 10.36 \pm 2.60,7.56 \pm 0.90$ and $7.78 \pm 0.60 \mu \mathrm{M}$ for BPH-1, $38.12 \pm 18.68,18.24 \pm 4.80$ and $11.12 \pm 1.84 \mu \mathrm{M}$ for $22 \mathrm{RV} 1$ cells, respectively. The data implied that the neuroleptic drug pimozide might hold a potential therapeutic index in treating prostate cancer.

Pimozide induces G0/G1 phase cell cycle arrest of prostate cancer cells. Next, the cellular morphological observation using light microscopy showed that after pimozide treatment for $24 \mathrm{~h}$ the prostate cancer cells DU145 and LNCaP displayed cytoplasmic shrinkage and the number of cells was reduced (Fig. 2A). In addition, to determine whether pimozide could induce cell cycle arrest to inhibit cell growth, we analyzed the effect of pimozide on the cell cycle distribution using PI staining. After DU145 and LNCaP cells were treated with $15 \mu \mathrm{M}$ pimozide for $24 \mathrm{~h}$, the population of cells in the $\mathrm{G} 0 / \mathrm{G} 1$ phase was increased significantly $(\mathrm{P}<0.01)$ whereas in the $\mathrm{S}$ phase it was decreased significantly $(\mathrm{P}<0.01)$ (Fig. 2B). After treatment with pimozide, DU145 cells showed a significant increase in the percentage of the G0/G1 phase cells, from 
A<smiles>O=c1[nH]c2ccccc2n1C1CCN(CCCC(c2ccc(F)cc2)c2ccc(F)cc2)CC1</smiles>

B

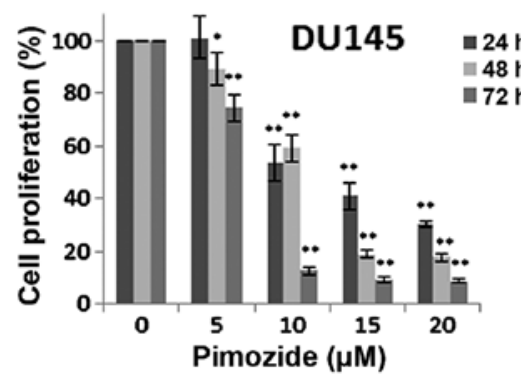

C

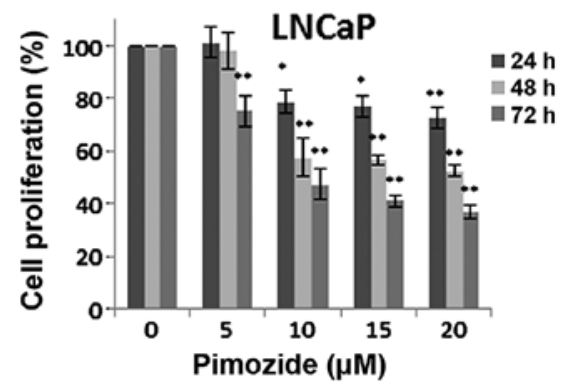

D
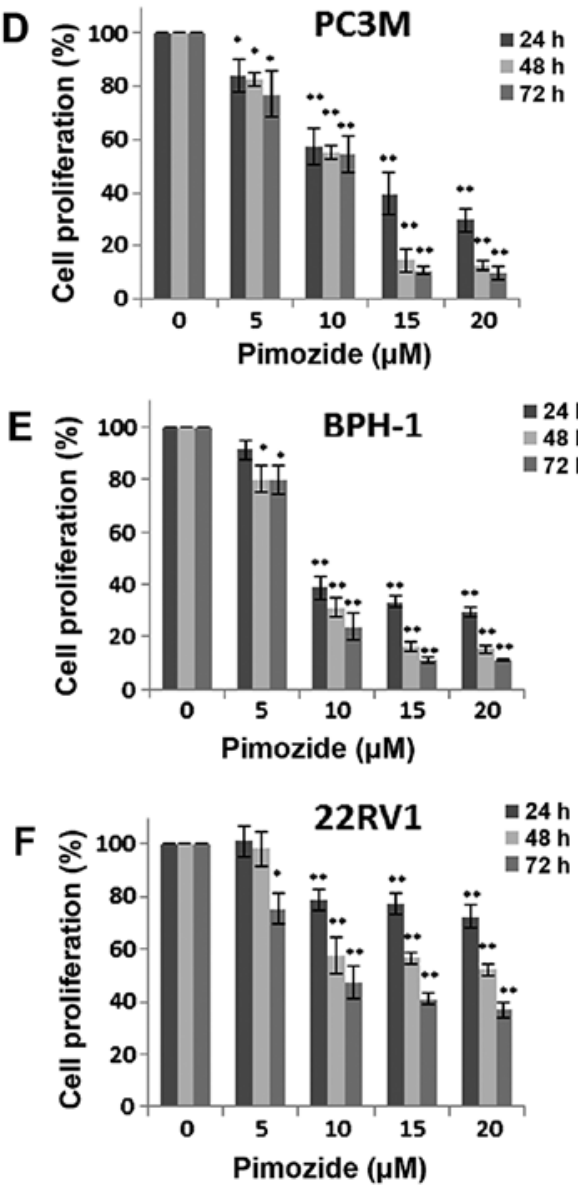

Figure 1. The antipsychotic agent pimozide inhibits cell growth of prostate cancer cells. (A) Chemical structure of pimozide. Prostate cancer cell lines (B) DU145, (C) LNCaP, (D) PC3M, (E) BPH-1 and (F) 22RV1 cells were treated with various concentrations of pimozide for various times, and cell viability was determined by MTT colorimetric assay. The results are shown as the mean values $\pm \mathrm{SD}$ of 3 independent experiments. ${ }^{*} \mathrm{P}<0.05,{ }^{* *} \mathrm{P}<0.01$ compared with the control.

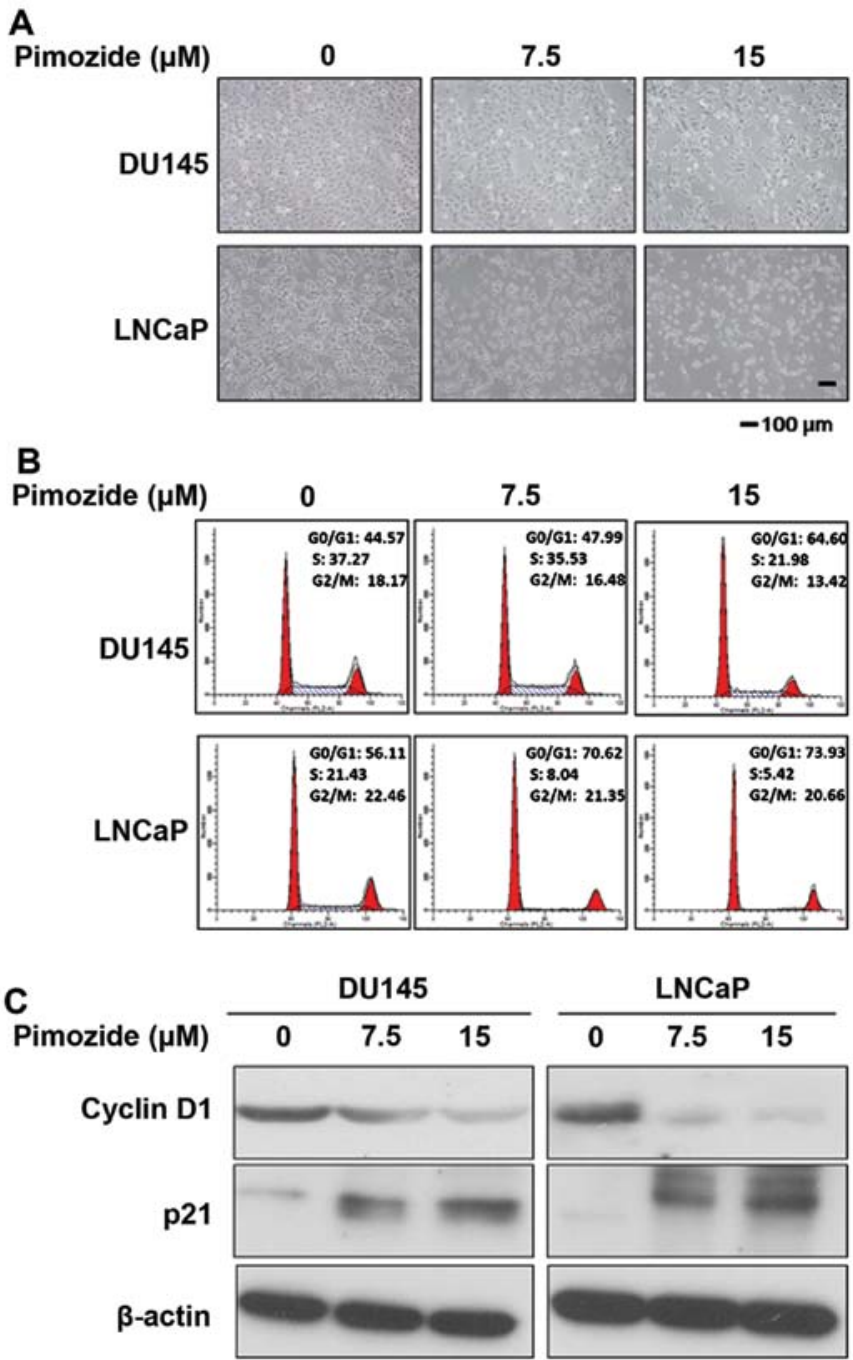

Figure 2. Pimozide induces G0/G1 phase cell cycle arrest of prostate cancer cells. (A) Inverted microscopic images (magnification, x100) of DU145 and LNCaP cells treated with the indicated concentrations of pimozide for $48 \mathrm{~h}$ are shown. (B) The cells stained with PI were subjected to flow cytometric analysis to determine the cell distributions at each phase of the cell cycle. Relative representative images are shown from 1 of 3 independent experiments. (C) Western blot analysis of the expression of cell cycle-related genes. Cell extracts were probed with antibodies against p21, cyclin D1 and $\beta$-actin (loading control) as indicated.

$44.57 \pm 2.04$ to $64.60 \pm 3.07 \%$, while $\mathrm{S}$ phase was reduced from $37.27 \pm 1.92$ to $21.98 \pm 1.38 \%$. Further examination of relative cell cycle marker showed remarkable increase of p21 levels and decrease of cyclin D1 level (Fig. 2C), consistent with the G0/G1 arrest phenomenon observed in the flow cytometric analysis. These results indicated that pimozide decreased viability of prostate cancer cells in association with G0/G1 phase cell cycle arrest.

Pimozide inhibits the ability of colony and sphere forming in prostate cancer cells. Furthermore, we examined whether pimozide inhibited the ability of colony and sphere forming in prostate cancer cells. Colony and sphere formation assay showed that pimozide inhibited the self-renewal capacity of prostate cancer cell lines DU145 and LNCaP in a dosedependent manner (Figs. 3 and 4). After treatment with $7.5 \mu \mathrm{M}$ pimozide for a week, DU145 cells had a decrease of 
A

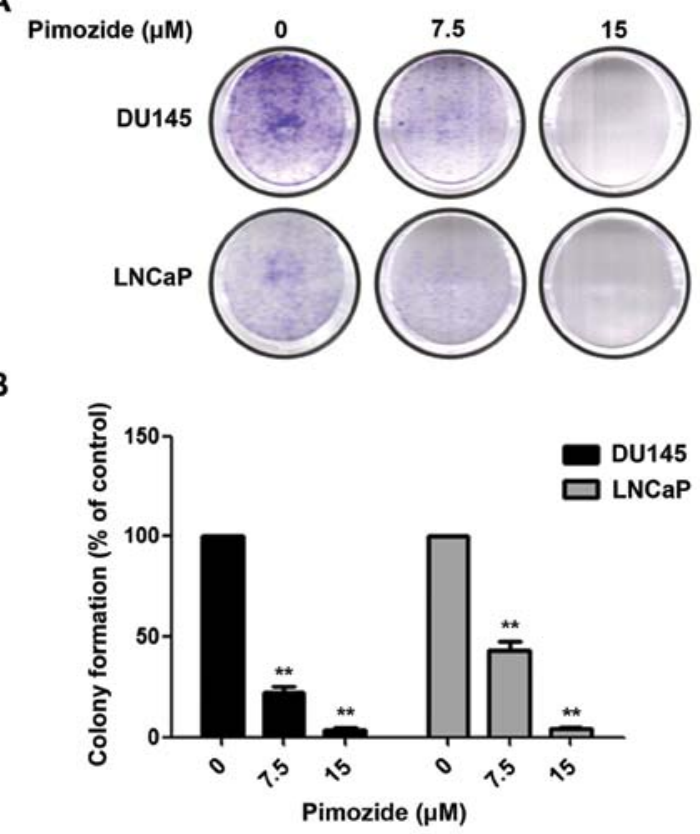

C

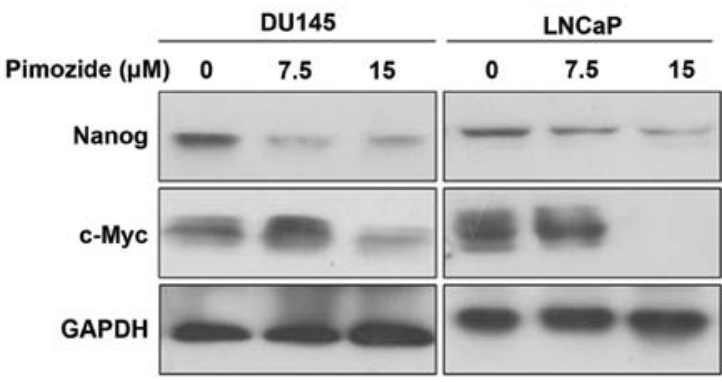

Figure 3. Pimozide inhibits the ability of colony forming in prostate cancer cells. DU145 and LNCaP cells were treated with various doses of pimozide for the indicated times. (A and B) Colony formation assay of prostate cancer cells treated with pimozide. The numbers of colonies were counted after staining with crystal violet to reveal the anticancer effect of pimozide treatment. (A) The graph indicates the number of colonies. (B) The results are from 3 independent experiments. The statistical results are shown, ${ }^{*} \mathrm{P}<0.05$, ${ }^{* *} \mathrm{P}<0.01$. (C) Western blot analysis of the stemness protein expression in prostate cancer cell lines DU145 and LNCaP. Cells were treated with the indicated concentrations of pimozide $(7.5$ and $15 \mu \mathrm{M})$ for $48 \mathrm{~h}$. The total cell lysate was subjected to SDS-PAGE and immunoblotted with antibodies against Nanog and c-Myc. GAPDH was used as an internal control.

$77.90 \pm 1.11 \%$ of the colonies (Fig. 3A and B). Sphere formation assay showed that the inhibition rate was $94.48 \pm 0.28 \%$ and $99.39 \pm 0.03 \%$ in DU145 cells treated with pimozide at the concentration of 7.5 and $15 \mu \mathrm{M}$, respectively (Fig. 4). Similar results, evaluated by colony and sphere formation assay, were shown in LNCaP cells with pimozide. In addition, western blot assay showed that prostate cancer cells DU145 and LNCaP treated with pimozide for $48 \mathrm{~h}$ significantly downregulated the expression level of the stemness genes Nanog and c-Myc (Fig. 3C). These results indicated pimozide inhibited the ability of colony and sphere forming in prostate cancer cells.

Pimozide suppresses cell migration in prostate cancer cells. As demonstrated in Fig. 5A and B, both DU145 and LNCaP cells suppressed the capacity of cell migration after treatment with 7.5 and $15 \mu \mathrm{M}$ pimozide compare to control without treatment
A

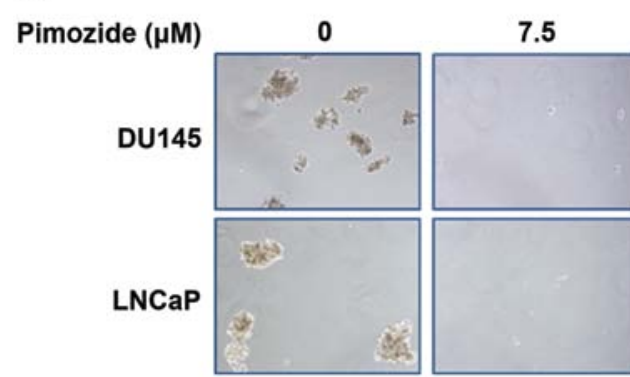

15

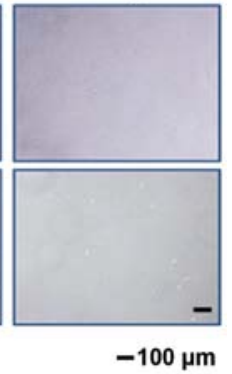

B

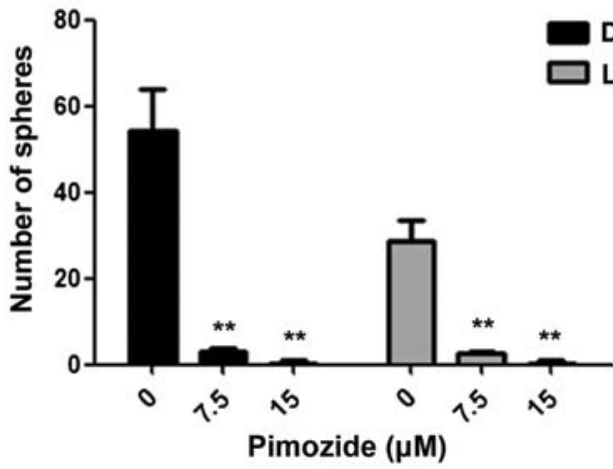

Figure 4. Pimozide inhibits the ability of sphere forming in prostate cancer cells. DU145 and LNCaP cells were treated with various pimozide for a week. (A and B) Sphere formation assay of prostate cancer cells treated with pimozide. The spheres were imaged under a light microscope (magnification, $\mathrm{x} 100)$, and the statistical results are shown. Data are the summary of three independent experiments, ${ }^{*} \mathrm{P}<0.05,{ }^{* *} \mathrm{P}<0.01$.

$(\mathrm{P}<0.01$, respectively). Using Transwell migration assay, the ability to migrate assessed in chambers without a matrix was also significantly reduced by $49.72 \pm 2.49 \%$ and $15.15 \pm 7.58 \%$ in the case of 7.5 and $15 \mu \mathrm{M}$ pimozide treated DU145 cells, respectively. In addition, $\mathrm{LNCaP}$ cells treated with $15 \mu \mathrm{M}$ pimozide had a decrease of $96.19 \pm 1.90 \%$ of migrated cells compare to control $(\mathrm{P}<0.01)$. We assessed whether pimozide inhibited cell migration through manipulating relative marker of epithelial-mesenchymal transition (EMT). Western blot assay showed that pimozide downregulated $\mathrm{N}$-cadherin expression and upregulated $\mathrm{E}$-cadherin expression in prostate cancer cells DU145 and LNCaP (Fig. 5C), suggesting that pimozide inhibited prostate cell migration through suppression of the EMT marker.

Pimozide suppresses the basal STAT3 activation and reverses the STAT3 activation induced by IL-6 in prostate cancer cells. It is clear that STAT3 signaling is of prime importance for promoting tumor progression and drug resistance as well as its potential as a therapeutic target in prostate cancer cells $(18,19)$. The activation of STAT3 signaling was reported with high expression of STAT3 phosphorylation at tyrosine 705 (pY-STAT3). Western blot analysis was performed to validate the expression of pY-STAT3. The results showed that pimozide reduced the basal expression of pY-STAT3 in both DU145 and LNCaP cells (Fig. 6A). Moreover, it is well known that IL-6 can activate STAT3 signaling to exert function in prostate cancer cells presenting high expression of pY-STAT3 

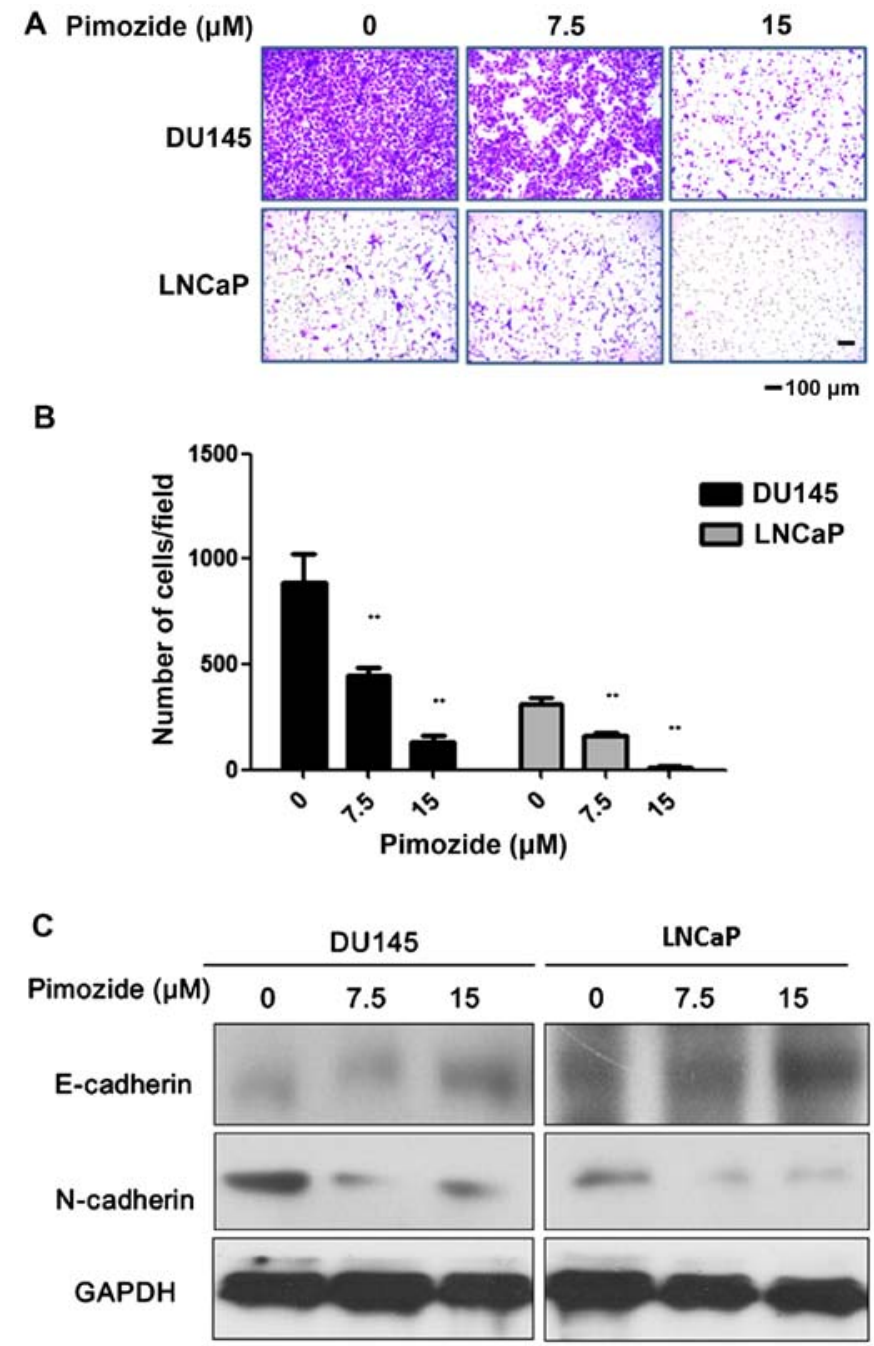

Figure 5. Pimozide suppresses cells migration in prostate cancer cells. Transwell migration assays of prostate cancer cells DU145 and LNCaP were treated with pimozide for $48 \mathrm{~h}$. (A) Images shown at a magnification of $\mathrm{x} 100$. (B) The data are a summary from 3 independent experiments, ${ }^{*} \mathrm{P}<0.05$, ${ }^{* *} \mathrm{P}<0.01$ compared to the control. (C) Western blot analysis of the expression of EMT-related markers. Cell extracts were probed with antibodies directed against E-cadherin, $\mathrm{N}$-cadherin and GAPDH (loading control) as indicated.

(Fig. 6B) $(20,21)$. Furthermore, pimozide treatment reversed the expression level of phosphorylation STAT3 at tyrosine 705 induced by IL-6 addition in DU145 and LNCaP cells (Fig. 6B). These data further suggested that pimozide may inhibit STAT3 signaling activity to suppress cell growth in prostate cancer cells.

\section{Discussion}

Currently, serious efforts are made in drug discovery and development for clinical treatment of prostate cancer (22). In our previous study, it is reported that the neuroleptic drug pimozide had antitumor activity against hepatocellular carcinoma cells or stem-like cells through suppressing the STAT3 activity and may be a novel candidate drug for treating advanced hepatocellular carcinoma (16). Since STAT3 signaling is important to cell proliferation, angiogenesis and drug resistance in prostate cancer, we concluded that pimozide
A

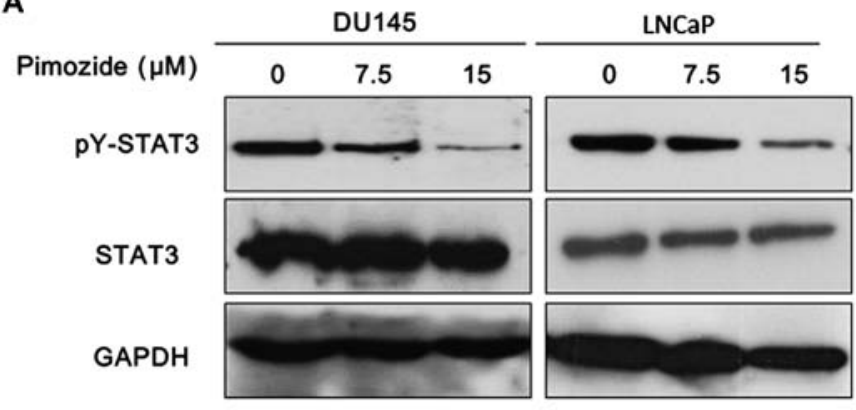

B

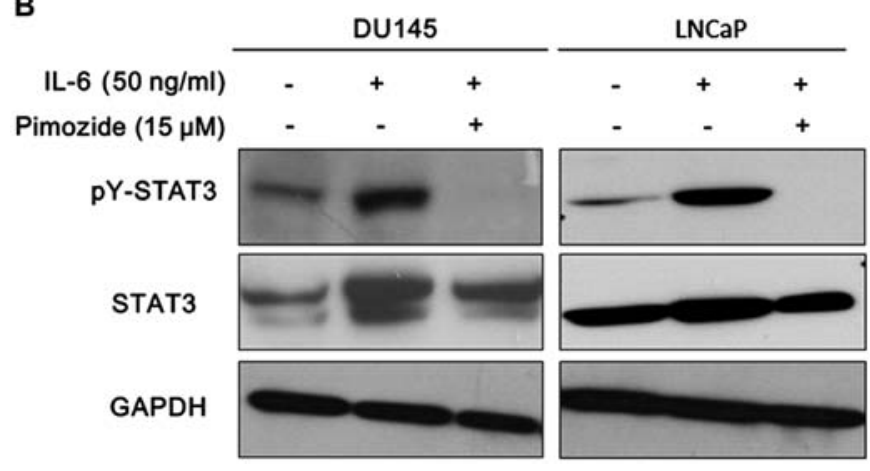

Figure 6. Pimozide suppresses the basal STAT3 activation and reverses the STAT3 activation induced by IL- 6 in prostate cancer cells. DU145 and $\mathrm{LNCaP}$ cells were treated with various doses of pimozide for $24 \mathrm{~h}$ before being subjected to western blot assay to analyse the change of cellular STAT3 activation. (A) Western blot analysis of the expression of STAT3 phosphorylation at tyrosine 705 (pY-STAT3) and total STAT3. DU145 and LNCaP cells were treated with $50 \mathrm{ng} / \mathrm{ml}$ IL-6, $15 \mu \mathrm{M}$ pimozide or a combination as indicated for $24 \mathrm{~h}$ and subjected to western blot analysis. (B) Western blot analysis of the expression of pY-STAT3 and total STAT3. GAPDH was used as an internal control. Representative images are shown.

also inhibited cellular proliferation of prostate cancer cells. In the present study, our results showed that pimozide inhibited cell proliferation of prostate cancer cells with G0/G1 phase cell cycle arrest, evaluated by MTT, colony and sphere formation assay. Additionally, pimozide suppressed cell migration in prostate cancer cells. The mechanism of action of pimozide was considered to be due to inhibition of STAT3 activation. It indicated that the antipsychotic agent pimozide may be a potential and novel therapeutic for patients with advanced prostate cancer.

Pimozide is a clinical drug approved by FDA to treat neuroleptic disorders. Since pimozide had relatively low side-effect and a broad spectrum of molecular targets, pimozide has been used to treat other diseases during the past 20 years, including monosymptomatic hypochondriacal psychoses, body dysmorphic disorder, metastatic melanoma, trichotillomania, and trigeminal and postherpetic neuralgia (23). Previous studies show that pimozide is a well-known antagonist of serotonin 5HT7 receptors $\left(\mathrm{K}_{\mathrm{i}}=0.5 \mathrm{nM}\right)$ for treating anti-depressant effect and of dopamine receptor D2 (D2R) $\left(\mathrm{K}_{\mathrm{i}}=0.33 \mathrm{nM}\right)$ for treating schizophrenia (24-26). However, in the present study, it is reported that pimozide shows potential for use as a new anticancer agent for treating prostate cancer.

Numerous studies have demonstrated constitutive activation of STAT3 in a wide variety of human malignancies, including head and neck, breast, lung, gastric, hepatocellular, 
colorectal and prostate cancers (27-29). Aberrantly STAT3 activation contributes to oncogenesis by preventing apoptosis, inducing cell proliferation, angiogenesis, invasion, and metastasis as well as suppressing antitumor immune responses $(30,31)$. Phosphorylated STAT3 dimerizes and translocates into the nucleus to bind to specific DNA response elements to induce the transcription of downstream genes, such as $B C L-x L$, $M C L 1$ and $c-M y c$ (32). Targeting STAT3 signaling results in suppression of the proliferation of various cancer cells in vitro and tumorigenicity in vivo $(33,34)$. Therefore, the identification and development of novel drugs targeting deregulated STAT3 activation effectively remains an important scientific and clinical challenge $(35,36)$. As yet, no direct STAT3 inhibitor has been approved for clinical use $(18,36)$. A previous study showed that pimozide suppressed the self-renewal capacity of chronic myelogenous leukemia cells by inhibiting the cellular transcription factor STAT5 activity (15). Surprisingly, our data showed that pimozide can inhibit STAT3 activation in prostate cancer, presenting that pimozide reduced the basal expression of pY-STAT3 in both DU145 and LNCaP cells and reversed the expression level of phosphorylation STAT3 at tyrosine 705 induced by IL- 6 addition. Similar results, reported by our previous work, were shown in hepatocellular carcinoma cells (16). Furthermore, another study showed that pimozide reduced STAT3 tyrosine phosphorylation in multiple myeloma cells (37). These further suggest that pimozide may be a novel and potential STAT3 inhibitor for anticancer treatment.

Although pimozide can induce cardiac toxicity, it has still not been reported to have adverse effects on other normal functional cells, such as hepatic or haematopoietic cells. A previous study showed that pimozide has almost no effect on haematopoietic progenitors derived from healthy donors (14). In addition, pimozide treatment was well tolerated with no significant effects on body weight in vivo (14). The lethal dose of pimozide is unknown for human. The LD50 is $228 \mathrm{mg} /$ $\mathrm{kg}$ in mice and $5120 \mathrm{mg} / \mathrm{kg}$ in rats. In our previous study, we adopted $25 \mathrm{mg} / \mathrm{kg}$ dose pimozide for in vivo treatment of hepatocellular carcinoma cells by oral gavage (PO), showing no significant effects on body weight (16). The dose of pimozide in the present study is relatively lower compared to the commonly used dose for treating clinical disease. Therefore, pimozide possibly is a safe drug for treating cancer. Besides in clinical application for many years, pimozide has the significance of a translational medicine in the clinical treatment of cancer.

In conclusion, the present study is to demonstrate whether the neuroleptic drug pimozide has antitumour activity against prostate cancer cells. Here, our results showed that pimozide inhibited cell proliferation of prostate cancer cells with G0/G1 phase cell cycle arrest, as well as suppressed cells migration. Moreover, pimozide can inhibit STAT3 activation in prostate cancer. Thus, an antipsychotic agent pimozide may be a potential and novel therapeutic for patients with advanced prostate cancer.

\section{Acknowledgements}

We thank members of Professor Qi Zhang laboratory, the Third Affiliated Hospital of Sun Yat-sen University for their critical comments. We also thank Vaccine Research
Institute of Sun Yat-sen University for technical and laboratory apparatus support. The present study was supported by the China Postdoctoral Science Foundation funded project (2014M562239 to J.-J.C.) and the PhD Start-up Fund of National Natural Science Foundation of Guangdong Province of China (to J.-J.C.).

\section{References}

1. Boguski MS, Mandl KD and Sukhatme VP: Drug discovery. Repurposing with a difference. Science 324: 1394-1395, 2009.

2. Del Barco S, Vazquez-Martin A, Cufí S, Oliveras-Ferraros C, Bosch-Barrera J, Joven J, Martin-Castillo B and Menendez JA: Metformin: Multi-faceted protection against cancer. Oncotarget 2: 896-917, 2011.

3. Hossain MA, Kim DH, Jang JY, Kang YJ, Yoon JH, Moon JO, Chung HY, Kim GY, Choi YH, Copple BL, et al: Aspirin induces apoptosis in vitro and inhibits tumor growth of human hepatocellular carcinoma cells in a nude mouse xenograft model. Int J Oncol 40: 1298-1304, 2012.

4. Triscott J, Lee C, Hu K, Fotovati A, Berns R, Pambid M, Luk M, Kast RE, Kong E, Toyota E, et al: Disulfiram, a drug widely used to control alcoholism, suppresses the self-renewal of glioblastoma and over-rides resistance to temozolomide. Oncotarget 3: 1112-1123, 2012.

5. Bashir MN: Epidemiology of prostate cancer. Asian Pac J Cancer Prev 16: 5137-5141, 2015 .

6. Karantanos T, Corn PG and Thompson TC: Prostate cancer progression after androgen deprivation therapy: Mechanisms of castrate resistance and novel therapeutic approaches. Oncogene 32: 5501-5511, 2013.

7. Barton BE, Karras JG, Murphy TF, Barton A and Huang HF: Signal transducer and activator of transcription 3 (STAT3) activation in prostate cancer: Direct STAT3 inhibition induces apoptosis in prostate cancer lines. Mol Cancer Ther 3: 11-20, 2004.

8. Ni Z, Lou W, Leman ES and Gao AC: Inhibition of constitutively activated Stat3 signaling pathway suppresses growth of prostate cancer cells. Cancer Res 60: 1225-1228, 2000.

9. Bishop JL, Thaper D and Zoubeidi A: The multifaceted roles of STAT3 signaling in the progression of prostate cancer. Cancers (Basel) 6: 829-859, 2014.

10. Egolf A and Coffey BJ: Current pharmacotherapeutic approaches for the treatment of Tourette syndrome. Drugs Today (Barc) 50: 159-179, 2014.

11. Taub RN and Baker MA: Treatment of metastatic malignant melanoma with pimozide. Lancet 1: 605, 1979.

12. Strobl JS, Kirkwood KL, Lantz TK, Lewine MA, Peterson VA and Worley JF III: Inhibition of human breast cancer cell proliferation in tissue culture by the neuroleptic agents pimozide and thioridazine. Cancer Res 50: 5399-5405, 1990.

13. Nelson EA, Walker SR, Weisberg E, Bar-Natan M, Barrett R, Gashin LB, Terrell S, Klitgaard JL, Santo L, Addorio MR, et al: The STAT5 inhibitor pimozide decreases survival of chronic myelogenous leukemia cells resistant to kinase inhibitors. Blood 117: 3421-3429, 2011.

14. Nelson EA, Walker SR, Xiang M, Weisberg E, Bar-Natan M, Barrett R, Liu S, Kharbanda S, Christie AL, Nicolais M, et al: The STAT5 inhibitor pimozide displays efficacy in models of acute myelogenous leukemia driven by FLT3 mutations. Genes Cancer 3: 503-511, 2012.

15. Strobl JS, Melkoumian Z, Peterson VA and Hylton H: The cell death response to gamma-radiation in MCF-7 cells is enhanced by a neuroleptic drug, pimozide. Breast Cancer Res Treat 51: 83-95, 1998.

16. Chen JJ, Cai N, Chen GZ, Jia CC, Qiu DB, Du C, Liu W, Yang Y, Long ZJ and Zhang Q: The neuroleptic drug pimozide inhibits stem-like cell maintenance and tumorigenicity in hepatocellular carcinoma. Oncotarget: May 27, 2015 (Epub ahead of print).

17. Levina V, Marrangoni AM, DeMarco R, Gorelik E and Lokshin AE: Drug-selected human lung cancer stem cells: Cytokine network, tumorigenic and metastatic properties. PLoS One 3: e3077, 2008.

18. Siveen KS, Sikka S, Surana R, Dai X, Zhang J, Kumar AP, Tan BK, Sethi G and Bishayee A: Targeting the STAT3 signaling pathway in cancer: Role of synthetic and natural inhibitors. Biochim Biophys Acta 1845: 136-154, 2014. 
19. Shodeinde AL and Barton BE: Potential use of STAT3 inhibitors in targeted prostate cancer therapy: Future prospects. Onco Targets Ther 5: 119-125, 2012.

20. Guo Y, Xu F, Lu T, Duan Z and Zhang Z: Interleukin-6 signaling pathway in targeted therapy for cancer. Cancer Treat Rev 38 : 904-910, 2012

21. Hodge DR, Hurt EM and Farrar WL: The role of IL-6 and STAT3 in inflammation and cancer. Eur J Cancer 41: 2502$2512,2005$.

22. Lin D, Wyatt AW, Xue H, Wang Y, Dong X, Haegert A, Wu R, Brahmbhatt S, Mo F, Jong L, et al: High fidelity patient-derived xenografts for accelerating prostate cancer discovery and drug development. Cancer Res 74: 1272-1283, 2014.

23. Lorenzo CR and Koo J: Pimozide in dermatologic practice: A comprehensive review. Am J Clin Dermatol 5: 339-349, 2004.

24. Seeman P: Atypical antipsychotics: Mechanism of action. Can J Psychiatry 47: 27-38, 2002.

25. Muscat R, Sampson D and Willner P: Dopaminergic mechanism of imipramine action in an animal model of depression. Biol Psychiatry 28: 223-230, 1990.

26. Chen X, Ji ZL and Chen YZ: TTD: Therapeutic target database. Nucleic Acids Res 30: 412-415, 2002.

27. Jing $\mathrm{N}$ and Tweardy DJ: Targeting Stat 3 in cancer therapy. Anticancer Drugs 16: 601-607, 2005.

28. Wendt MK, Balanis N, Carlin CR and Schiemann WP: STAT3 and epithelial-mesenchymal transitions in carcinomas. JAKSTAT 3: e28975, 2014.

29. Teng Y, Ross JL and Cowell JK: The involvement of JAK-STAT3 in cell motility, invasion, and metastasis. JAKSTAT 3: e28086, 2014.
30. Al Zaid Siddiquee K and Turkson J: STAT3 as a target for inducing apoptosis in solid and hematological tumors. Cell Res 18: 254-267, 2008

31. Wang X, Crowe PJ, Goldstein D and Yang JL: STAT3 inhibition, a novel approach to enhancing targeted therapy in human cancers (Review). Int J Oncol 41: 1181-1191, 2012.

32. Yu H, Kortylewski M and Pardoll D: Crosstalk between cancer and immune cells: Role of STAT3 in the tumour microenvironment. Nat Rev Immunol 7: 41-51, 2007.

33. Gurbuz V, Konac E, Varol N, Yilmaz A, Gurocak S, Menevse S and Sozen S: Effects of AG490 and S3I-201 on regulation of the JAK/STAT3 signaling pathway in relation to angiogenesis in TRAIL-resistant prostate cancer cells in vitro. Oncol Lett 7: 755-763, 2014.

34. Han Z, Wang X, Ma L, Chen L, Xiao M, Huang L, Cao Y, Bai J, Ma D, Zhou J, et al: Inhibition of STAT3 signaling targets both tumor-initiating and differentiated cell populations in prostate cancer. Oncotarget 5: 8416-8428, 2014.

35. Zhao M, Jiang B and Gao FH: Small molecule inhibitors of STAT3 for cancer therapy. Curr Med Chem 18: 4012-4018, 2011.

36. Mankan AK and Greten FR: Inhibiting signal transducer and activator of transcription 3: Rationality and rationale design of inhibitors. Expert Opin Investig Drugs 20: 1263-1275, 2011.

37. Nelson EA, Sharma SV, Settleman J and Frank DA: A chemical biology approach to developing STAT inhibitors: Molecular strategies for accelerating clinical translation. Oncotarget 2: 518-524, 2011. 